\title{
Use of electronic medical records differs by specialty and office settings
}

\author{
Erik W J Kokkonen, ${ }^{1}$ Scott A Davis, ${ }^{1}$ Hsien-Chang Lin, ${ }^{2}$ Tushar S Dabade, ${ }^{1}$ \\ Steven R Feldman, ${ }^{1,3,4}$ Alan B Fleischer $\mathrm{Jr}^{1}$
}

'Departments of Dermatology, Center for Dermatology Research, Wake Forest School of Medicine, Winston-Salem, North Carolina, USA

${ }^{2}$ Department of Applied Health Science, School of Public Health, Indiana University, Bloomington, Indiana, USA ${ }^{3}$ Departments of Pathology, Center for Dermatology Research, Wake Forest School of Medicine, Winston-Salem, North Carolina, USA

${ }^{4}$ Departments of Public Health Sciences, Center for Dermatology Research, Wake Forest School of Medicine, Winston-Salem, North Carolina, USA

\section{Correspondence to} Scott A Davis, Department of Dermatology, Center for Dermatology Research Wake Forest School of Medicine, Medical Center Boulevard, Winston-Salem NC 27157-1071, USA; scdavis@wakehealth.edu

Received 31 December 2012 Revised 7 March 2013 Accepted 10 March 2013 Published Online First 28 March 2013

To cite: Kokkonen EWJ, Davis SA, Lin H-C, et al. J Am Med Inform Assoc 2013;20:e33-e38.

\section{ABSTRACT}

Objective To assess differences in the use of electronic medical records (EMRs) among medical specialties and practice settings.

Methods A cross-sectional retrospective study using nationally representative data from the National Ambulatory Medical Care Survey for the period 2003-2010 was performed. Bivariate and multivariate analyzes compared EMR use among physicians of 14 specialties and assessed variation by practice setting. Differences in EMR use by geographic region, patient characteristics, and physician office settings were also assessed.

Results Bivariate and multivariate analysis demonstrated increased EMR use from 2003 to 2010, with $16 \%$ reporting at least partial use in 2003 , rising to $52 \%$ in $2010(p<0.001)$. Cardiologists, orthopedic surgeons, urologists, and family/general practitioners had higher frequencies of EMR use whereas psychiatrists, ophthalmologists, and dermatologists had the lowest EMR use. Employed physicians had higher EMR uptake than physicians who owned their practice $(48 \%$ vs $31 \%$, $p<0.001)$. EMR uptake was lower among solo practitioners $(23 \%)$ than non-solo practitioners $(42 \%$, $\mathrm{p}<0.001)$. Practices owned by Health Maintenance Organizations had higher frequencies of EMR use (83\%) than practices owned by physicians, community health centers, or academic centers (all $<45 \%, p<0.001)$. Patient demographics did not affect EMR use ( $p>0.05)$. Conclusions Uptake of EMR is increasing, although it is significantly slower in dermatology, ophthalmology, and psychiatry. Solo practitioners and owners of a practice have low frequencies of EMR use compared with non-solo practitioners and those who do not own their practice. Despite incentives for EMR adoption, physicians should carefully weigh which, if any, EMR to adopt in their practices.

\section{INTRODUCTION}

Electronic medical records (EMRs) have been touted as a way to reduce medical errors, consolidate medical records, reduce costs, and increase coordination and quality of patient care. ${ }^{1-4}$ Although there is no federal requirement for physicians to use EMRs, the federal government has incentivized the use of EMRs by subsidizing physicians and hospitals for adopting 'meaningful use' of certified EMRs in their practice. ${ }^{5}$ Meaningful use has been defined to mean that certified EMR programs should result in healthcare that emphasizes prevention, efficiency, evidence-based medicine, and is patient-centered, with more specific criteria to be implemented in stages. ${ }^{6}$ The American Recovery and Reinvestment Act (ARRA) of 2009 delineates three main components of meaningful use: (1) EMR must be used in a meaningful way, such as for prescriptions; (2) EMR must involve exchanging health information electronically to improve healthcare quality; (3) EMR technology must be used for submitting clinical measures and quality. $^{78}$

Under the ARRA, the federal government has allocated $\$ 17$ billion in incentives for purchase and adoption of EMRs. These incentives include up to $\$ 18000$ in extra Medicare payments during the first year of implementation if done in 2011 or 2012 , which can total $\$ 44000$ over 5 years. $^{7}{ }^{9}$ Reimbursement will be less if physicians implement EMRs after 2012. Furthermore, physicians who do not demonstrate meaningful use of certified electronic health records will receive deductions from their reimbursement for services provided to Medicare and Medicaid patients effective from 2015. The deductions begin at $1 \%$ in 2015 , increase to $2 \%$ in 2016 , and become $3 \%$ in $2017 .{ }^{9}$

Although implementation of EMRs among physicians is increasing, the rate of adoption has, until recently, been relatively slow, especially among small and independent practices. ${ }^{10-12}$ Commonly cited barriers to establishing EMRs in the office setting include initial costs and costs of maintenance, concern over slowing of the physician's pace and workflow, uncertainty over which of the many EMR products and software is most user-friendly, and concerns over technical support and whether a given EMR program will become obsolete. ${ }^{13} 14$

The purpose of this study was to assess the trends in EMR implementation among the various medical specialties and office settings practicing within ambulatory medicine in the USA. By demonstrating which specialties and office settings have had slower rates of adoption to date, the study seeks to identify targets for future incentive programs.

\section{METHODS}

We used data from the National Ambulatory Medical Care Survey (NAMCS) to assess the use of EMRs from 2003 to 2010. The NAMCS has collected data from 1973 to 1981 , in 1985 , and annually since 1989 from non-federal employed physicians about outpatient visits in the USA. The NAMCS uses a multistage probability design to obtain its data. The first stage consists of obtaining samples from 112 primary sampling units (PSU) out of the roughly 1900 such units into which the 50 states and District of Columbia is divided. The second stage involves obtaining a sample of practicing physicians from each PSU. The final stage 
consists of random samples of office visits from the practices of sample physicians. These sample physicians were divided into 52 subsamples of physicians, each of which was randomly assigned a different 7-day reporting period. During these reporting periods, a random systematic sample of visits was selected. Data are recorded by the physician or staff regarding the reason for the visit, symptoms, diagnoses, medications prescribed and/ or provided, and demographics of patients and the services provided. Visits to hospitalists, anesthesiologists, pathologists, and radiologists are excluded from the NAMCS data. In the final report, the number of survey responses by physician specialty were adjusted according to the proportion of total physicians that each specialty represents. ${ }^{15} 16$

We analysed data from 2003 to 2010 to determine the proportion of physician visits with partial and full use of EMRs. The year 2003 was chosen because a previous study using NAMCS data had demonstrated no change in EMR use from 2001 to $2003 .{ }^{17}$ We assessed the use of EMRs among the 14 medical specialties classified by the NAMCS. The NAMCS uses the system of specialty classification defined by the National Center for Health Statistics (NCHS), a separate system from those used by the American Board of Medical Specialties or American Medical Association. ${ }^{15}$ Full and/or partial use of EMRs is presented as a separate survey question from use of EMRs for billing. The NAMCS survey allowed physicians to state they had full use, partial use, no use, or were unsure whether they had use of EMRs.

We also assessed the influence of patient characteristics on EMR use. The NAMCS allows physicians to record patient characteristics such as age, gender, and race for each visit. We divided age into 10-year increments (0-9, 10-19, 20-29, etc). Race was divided into Caucasian, African-American, and other, which is consistent with the categories used by the NAMCS.

Further, we explored physician practice characteristics on EMR use. The NAMCS asked physicians, 'Is this a solo practice?' for which we divided the answers into 'Yes' and 'No'. We further analyzed the data to determine the proportion of solo practices by specialty, as we hypothesized that, if there was a significant difference in EMR use among specialties, the specialties with lower frequencies of EMR use may have a higher proportion of solo practitioners. Our reasoning was that, if the cost of EMR was a barrier for implementation, solo practitioners may face larger barriers without other group members to share in the costs.

Type of office setting for each visit was assessed by physician responses to 'Type of Office Setting for this Visit'. Responses were divided into private practice, Health Maintenance Organization (HMO), and others (community health center, mental health center, non-federal government clinic, and family planning clinic). Employment status of the physician was also assessed, dividing the responses into owner of the practice or non-owner.

We further analyzed differences in EMR use by geography. The categories for geography included North, South, Midwest, and West based on the NAMCS methodology for grouping the geographic regions of the ambulatory visits.

Bivariate analysis was performed using software to conduct linear regression and $\chi^{2}$ testing (SAS/STAT software, SAS Institute). For multivariate analysis, a logistic regression was performed to explore the use of EMR among physician specialties, adjusting for physician specialty, year, practice ownership status, office type, and geographic region (STATA V.11.0, Stata, College Station, Texas, USA). The logistic regression was weighted using the NAMCS sampling and weighting scheme. For the purposes of logistic regression, 'partial' and 'full' EMR use were combined as using EMR. The office setting variable was categorized as HMO, private or group practice, and other. The study was declared exempt by the Wake Forest University Institutional Review Board.

\section{RESULTS}

\section{Bivariate analysis}

From 2003 to 2010 the NAMCS sampled 228965 physician office visits, which estimate the experience of 6.73 billion total ambulatory visits. Primary care physicians (obstetrics and gynecology, family and general practice, pediatrics, and internal medicine) accounted for 102965 responses (45.0\%), while surveys from specialists represented 126000 responses (55.0\%). Across all specialties combined, the reported full and partial use of EMRs increased from 2003 to 2010 (figure 1). The surveys in 2003 and 2004 did not differentiate between full and partial use of EMRs. During those 2 years, use of EMR (whether full use or partial use) increased. The full use of EMRs in 2010 among all specialties was $39 \%$, which represents a 3\% increase from the previous year and a $127 \%$ increase from 2005. At least partial use of EMRs in 2010 was 52\%, which was 3\% higher than in 2009 and $100 \%$ higher than in 2005. EMR use was highest among urologists, general and family physicians, oncologists, pediatricians, and orthopedic surgeons and was lowest among psychiatrists, ophthalmologists, and dermatologists (figure 2).

Increases over the period from 2003 to 2010 varied from $74.1 \%$ in otolaryngology to $397.2 \%$ in urology (table 1 ). The specialties with the lowest frequencies of use still saw large increases over time: $294.2 \%$ in psychiatry, $229.2 \%$ in dermatology, and $131.3 \%$ in ophthalmology.

Physicians' employment status was another factor in EMR use. Use of at least partial EMR among physicians who were employed (48\%) was higher than EMR use among physicians who owned their practice $(48 \%$ vs $31 \%$; p < 0.001$)$. EMR use was also dependent on whether or not a physician was in solo practice, with EMR use among solo practitioners of $23 \%$ compared with $42 \%$ among those not in solo practice $(\mathrm{p}<0.001)$. The specialties with higher proportions of solo practitioners had lower frequencies of EMR use than specialties with lower proportions of solo practitioners (figure 3 ).

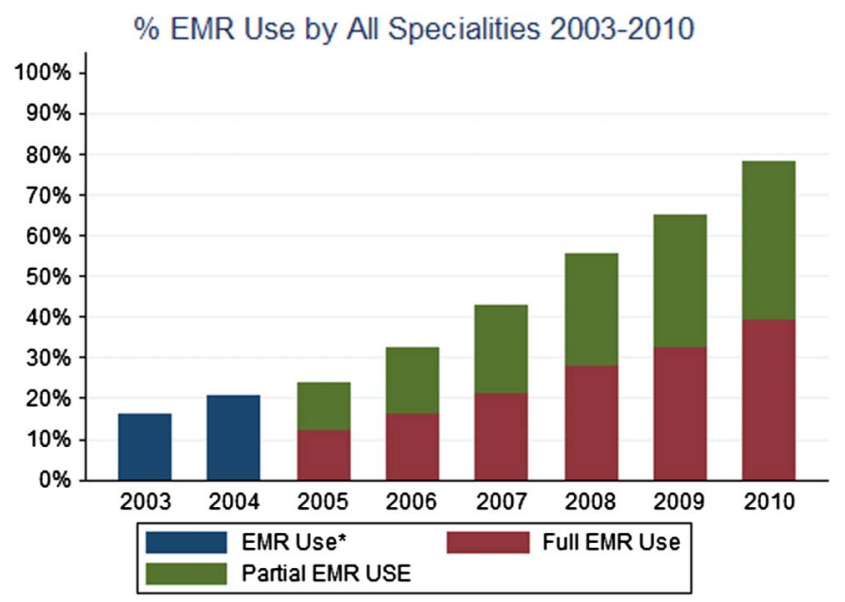

Figure 1 Proportion of ambulatory office visits from 2003 to 2010 among all specialties with use of electronic medical records (EMRs). Note that National Ambulatory Medical Care Survey data from 2003 to 2004 did not delineate full from partial EMR use. 


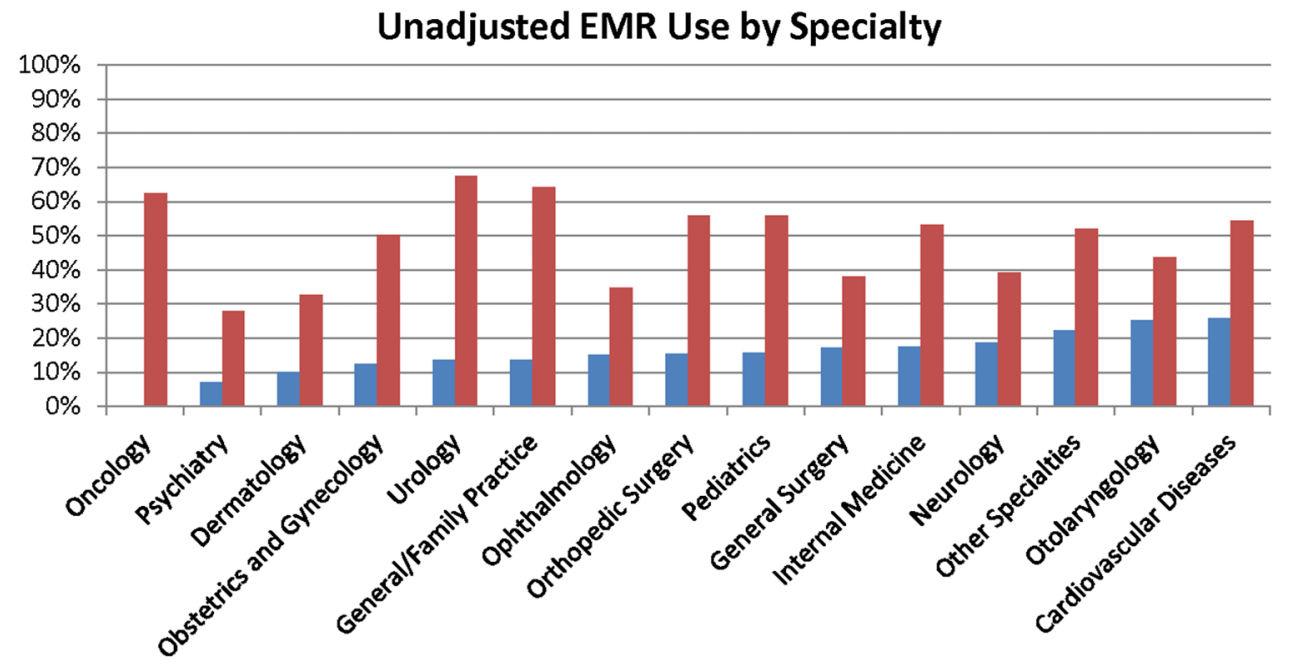

-2003 $\square 2010$

Figure 2 Cumulative frequencies of electronic medical record (EMR) use among 14 different medical specialties from 2003 to 2010 . Percentages represent unadjusted frequencies and represent both part and full EMR use combined. $p<0.0001$ for the difference between 2003 and 2010 frequencies in all specialties listed. The oncology stratum was not sampled in 2003.

There were also different frequencies of at least partial EMR use according to practice ownership (figure 4). Physician or physician group ownership was associated with 32\% EMR use while HMO ownership of the practice demonstrated an EMR use of $83 \%$, community health center ownership was associated with EMR use of $42 \%$, and medical/academic health center ownership with $40 \%$ (all $\mathrm{p}<0.001$ ). There was no provision in the NAMCS survey that allowed physicians to state the number of physicians in their group.

Physician office visits in the West were more likely to be associated with EMR use than visits in the Northeast, Midwest, and South $(p<0.01)$. There was no statistically significant difference in EMR use when comparing patient characteristics of race, sex, or age $(\mathrm{p}>0.05)$.

Table 1 Growth rate of electronic medical record (EMR) use from 2003 to 2010

\begin{tabular}{llll}
\hline & \multicolumn{2}{l}{ EMR use (\%) } & \\
\cline { 2 - 3 } & \multicolumn{2}{l}{ Growth rate from } \\
Specialty & 2003 & 2010 & 2003 to 2010 (\%) \\
\hline General/family practice & 13.7 & 64.2 & 369.6 \\
Internal medicine & 17.6 & 53.1 & 201.9 \\
Pediatrics & 15.8 & 55.9 & 254.4 \\
General surgery & 17.2 & 37.9 & 120.8 \\
Obstetrics and gynecology & 12.5 & 50.2 & 300.8 \\
Orthopedic surgery & 15.5 & 56.0 & 262.3 \\
Cardiovascular diseases & 25.7 & 54.5 & 112.2 \\
Dermatology & 10.0 & 32.8 & 229.2 \\
Urology & 13.6 & 67.5 & 397.2 \\
Psychiatry & 7.1 & 28.0 & 294.2 \\
Neurology & 18.8 & 39.2 & 109.2 \\
Ophthalmology & 15.0 & 34.7 & 131.3 \\
Otolaryngology & 25.1 & 43.6 & 74.1 \\
Other specialties & 22.3 & 52.0 & 133.3 \\
Oncology & - & 62.4 & - \\
\hline Data source: National Ambulatory Medical Care Survey (NAMCS) & 2003 and 2010. \\
Data for oncology not available in NAMCS 2003. & & \\
& & & \\
\hline
\end{tabular}

\section{Multivariate analysis}

There were 192179 sampled office visits representing over 6.5 billion total office visits included in the multivariate analysis. This differs somewhat from the figures in the bivariate analysis since the data from 2006 were dropped in the multivariate analysis due to collinearity. There was a significant time trend of increasing use of EMR since 2003 (table 2). General and family practice had the highest frequencies of EMR use and, while other specialties had similar ORs of EMR use, these were not statistically significant. Compared with general and family practitioners, EMR use was lowest among dermatologists, ophthalmologists, and psychiatrists $(\mathrm{OR}=0.52, \mathrm{p}<0.01 ; \mathrm{OR}=0.60$, $\mathrm{p}<0.01 ; \mathrm{OR}=0.34, \mathrm{p}<0.001$, respectively).

Office setting was also a predictor of EMR use. Physician practice owners were less likely to use EMR than non-owners $(\mathrm{OR}=0.61, \mathrm{p}<0.01)$, and physicians in HMOs and other

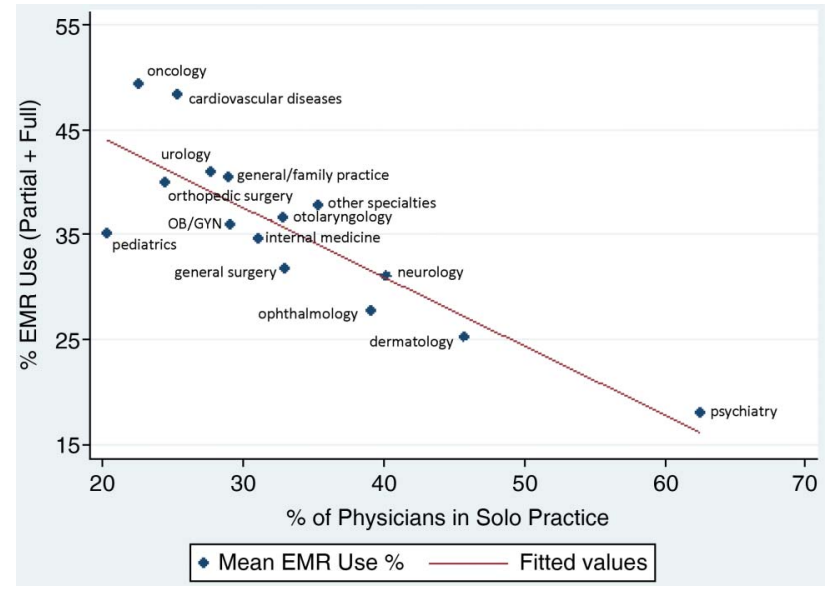

Figure 3 Proportion of electronic medical record (EMR) use and proportion of solo practitioners by specialty type. Proportion of solo practitioners by specialty was determined by the number of physicians who reported being in solo practice to the National Ambulatory Medical Care Survey. 


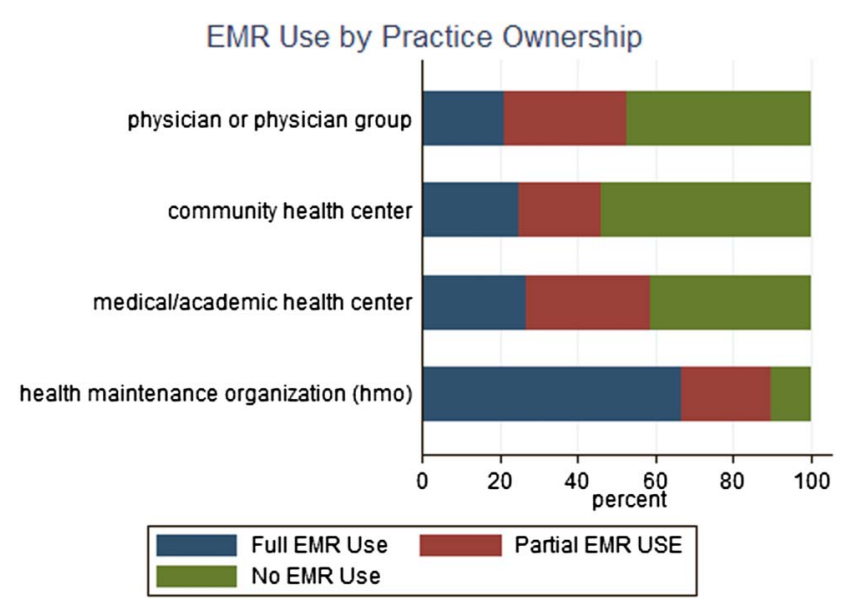

Figure 4 Proportion of electronic medical record (EMR) use by practice ownership.

prepaid office settings were much more likely to use EMR than physicians in private solo or group practices $(\mathrm{OR}=0.24$, $\mathrm{p}<0.001)$ or other practice settings $(\mathrm{OR}=0.33, \mathrm{p}<0.001)$. Geographic region was not a determinant of EMR use after adjusting for physician specialty, office setting, ownership status, and year (table 2).

\section{DISCUSSION}

The use of EMRs among all physicians has been rising since 2003. Financial incentives will most likely continue to increase EMR adoption, and even the three lagging specialties had more than doubled their EMR use since 2003. However, EMR use among the different medical specialties varied widely between 2003 and 2010, with three specialties (ophthalmology, dermatology, and psychiatry) significantly lagging behind the others.

Uptake of EMR among solo practitioners has been slower than for non-solo practitioners. The three specialties with the lowest frequencies of EMR use were among the specialties with highest rates of solo practitioners (figure 3). The likelihood of EMR adoption increases with the number of physicians in a medical group. ${ }^{18}$ One recent study demonstrated that the use of EMRs was $17.2 \%$ in practices with $1-2$ physicians, $38.2 \%$ in practices with $3-7$ physicians, and $44.8 \%$ in practices with $8-12$ physicians. ${ }^{19}$ With the significant costs of EMR implementation and annual maintenance, solo practitioners may find it more difficult to share the costs of EMR than those in a group practice or those employed by larger organizations. However, gaps in EMR use may be narrowed by the reimbursements for EMR implementation provided by the ARRA.

A Congressional Budget Office (CBO) study suggested that office-based providers may see little benefit to adopting EMRs because many of the administrative benefits that EMR is designed to create can only be seen by providers who are part of an integrated healthcare delivery system. In fact, the CBO further suggests that office-based providers may in fact lose money from EMRs. ${ }^{20}$ Another paper with a wide literature review concluded that there were insufficient data to make costeffectiveness conclusions regarding EMR adoption. ${ }^{1}$ Others have demonstrated possible, but modest, financial benefits. ${ }^{13}$ The relatively small incentives available are perhaps insufficient to motivate physicians in some settings to adopt EMRs.

Another possible contributing factor to varying frequencies of EMR use among different specialties is that, until recently, many of the EMR software programs tended to be 'one-size-fits-all'
Table 2 Logistic regression results of electronic medical record use adjusting for physician specialty, region, office setting, payment source, and year

\begin{tabular}{|c|c|c|c|}
\hline Variable & $\mathrm{OR}$ & $95 \% \mathrm{Cl}$ & p Value \\
\hline \multicolumn{4}{|l|}{ Specialty } \\
\hline General and family practice & (Ref) & - & - \\
\hline Internal medicine & 1.08 & (0.82 to 1.42 ) & 0.58 \\
\hline Pediatrics & 0.90 & (0.70 to 1.17$)$ & 0.44 \\
\hline General surgery & 0.86 & (0.62 to 1.19 ) & 0.36 \\
\hline Obstetrics and gynecology & 0.85 & (0.64 to 1.13$)$ & 0.28 \\
\hline Orthopedic surgery & 1.31 & (0.99 to 1.73 ) & 0.06 \\
\hline Cardiovascular diseases & 1.40 & (0.97 to 2.03 ) & 0.07 \\
\hline Dermatology & $0.52^{* *}$ & (0.36 to 0.76$)$ & 0.00 \\
\hline Urology & 1.34 & (0.98 to 1.82 ) & 0.06 \\
\hline Psychiatry & $0.34^{* *}$ & (0.24 to 0.49$)$ & $<0.001$ \\
\hline Neurology & 0.86 & (0.62 to 1.20$)$ & 0.38 \\
\hline Ophthalmology & $0.60 * *$ & (0.43 to 0.83$)$ & 0.00 \\
\hline Otolaryngology & 1.02 & (0.72 to 1.44$)$ & 0.91 \\
\hline All other specialties & 1.04 & (0.80 to 1.35$)$ & 0.79 \\
\hline \multicolumn{4}{|l|}{ Practice region } \\
\hline Northeast & (Ref) & - & - \\
\hline Midwest & 1.17 & (0.91 to 1.51$)$ & 0.21 \\
\hline South & 1.00 & (0.78 to 1.29$)$ & 0.98 \\
\hline West & 1.27 & (0.94 to 1.72$)$ & 0.12 \\
\hline \multicolumn{4}{|l|}{ Physician employment status } \\
\hline Owner & 0.61 ** & (0.51 to 0.74$)$ & $<0.001$ \\
\hline Employee/contractor & (Ref) & - & - \\
\hline \multicolumn{4}{|l|}{ Office type } \\
\hline Private solo or group practice & $0.24^{* *}$ & (0.17 to 0.33 ) & $<0.001$ \\
\hline HMO or other prepaid practice & (Ref) & - & - \\
\hline Other office types & $0.33^{* *}$ & (0.23 to 0.47$)$ & $<0.001$ \\
\hline \multicolumn{4}{|l|}{ Primary payment source } \\
\hline Private insurance & (Ref) & - & - \\
\hline Medicare & 0.99 & (0.91 to 1.07 ) & 0.78 \\
\hline Medicaid & $0.82^{*}$ & (0.70 to 0.97$)$ & 0.02 \\
\hline Other source & $0.83^{*}$ & (0.72 to 0.96$)$ & 0.01 \\
\hline \multicolumn{4}{|l|}{ Year dummy } \\
\hline Year 2003 & (Ref) & - & - \\
\hline Year 2004 & 1.38 & (0.99 to 1.92$)$ & 0.06 \\
\hline Year 2005 & $1.93^{* *}$ & (1.33 to 2.79$)$ & 0.00 \\
\hline Year 2006 & (Omitted) & - & - \\
\hline Year 2007 & $2.87^{* *}$ & (1.99 to 4.12 ) & $<0.001$ \\
\hline Year 2008 & $4.88^{* *}$ & (3.46 to 6.87 ) & $<0.001$ \\
\hline Year 2009 & $6.21^{* *}$ & (4.37 to 8.82 ) & $<0.001$ \\
\hline Year 2010 & $6.38^{* *}$ & (4.49 to 9.06$)$ & $<0.001$ \\
\hline \multicolumn{4}{|c|}{$\begin{array}{l}\text { Data source: National Ambulatory Medical Care Survey (NAMCS) 2003-2 } \\
\text { Year } 2006 \text { was omitted because of collinearity. } \\
\text { Unweighted sample size } 192179 \text {; weighted sample size } 6499132715 . \\
{ }^{*} p<0.05,{ }^{* *} p<0.01 \text {. }\end{array}$} \\
\hline
\end{tabular}

with features and tabs that may be valuable for some specialties but not others. ${ }^{21}$ Recently, however, software companies have developed more specific EMR software programs for individual specialties. It is unclear what effect, if any, these targeted EMR software programs will have on EMR implementation rates in the near future within these specialties. However, a recent study showed that, as of 2011, intention to apply for EMR meaningful use incentives still varied widely among specialties, from $15 \%$ in psychiatry to $82 \%$ in cardiovascular disease. ${ }^{22}$ The adoption of EMRs in psychiatry may be hampered by strict regulations governing privacy and security of behavioral health 
records. System integration, such as image management solutions for ophthalmology and dermatology, appears to be another specialty-specific obstacle. Thus, skepticism about the benefits of EMRs seems to persist in the slower-adopting specialties despite new features and incentives.

One limitation of this study is that the NAMCS has up-to-date publicly available data through 2010, which cannot examine the full effects of the federal government's incentives toward EMR adoption, much of which started to occur in late 2009. These incentives will probably continue the increased use of EMRs; recent NCHS studies estimate that the overall frequency rose to $57 \%$ in 2011 and $72 \%$ in $2012 .^{23} 24$ This study also did not examine year-by-year trends within each specialty, allowing for the possibility that a specialty has more recently made significant strides toward EMR uptake that may not be reflected by a significantly lower overall frequency of EMR use from 2003 to 2010. In addition, physician age was not provided, so the NAMCS does not permit assessment of generational differences in EMR adoption patterns. The general question asked in the survey about full or partial EMR use does not show whether use is sufficient to meet meaningful use criteria.

EMRs have the potential to enhance organization, lower costs in some settings, and reduce errors. However, industry experts contend that the EMR software market lacks a clear leader or standard bearer because EMR design and usability is still developing. ${ }^{25}$ While universal EMR implementation ultimately seems inevitable, adopting EMRs simply for the sake of adoption may prove to be detrimental, as evidenced by a 2001 study which illustrated physician disenchantment and significant time and autonomy concerns after 6 months' use of EMR. ${ }^{26}$ Other studies since that time have suggested wider acceptance and satisfaction with EMRs. However, although EMR software has a high probability of improving care and workflow, its adoption cannot in and of itself guarantee what it has been touted to do. ${ }^{27}$ Although the theoretical benefits of EMRs are convincing, two recent studies demonstrated that EMRs have not yet significantly improved quality of care. ${ }^{29} 30$

\section{CONCLUSIONS}

For physicians who are looking to implement EMRs, there are many potentially positive reasons for doing so: better coordination of patient care, organization of patient files, improvement in providing preventative services, reduction of redundant laboratory tests, and drug interaction warnings- to name a few. With federal incentives through 2014, much of the cost of EMRs can be offset by demonstrating meaningful use of EMRs. However, EMRs are clearly continuing to evolve, and will undoubtedly improve as physicians provide more feedback and market forces support the software that demonstrates ease of use and better patient care. This study suggests that there are significant discrepancies in EMR use among specialties and physician office characteristics which provide an opportunity for both physicians and EMR developers to address, and for government to design appropriate incentives. For now, physicians should carefully weigh whether the impact of EMRs on patient care and reimbursement for EMR adoption justify entering 'uncharted' territory.

Contributors $A B F$ takes full responsibility for the integrity of the data and analysis. EWJK drafted the manuscript and interpreted the data. SAD and $\mathrm{H}-\mathrm{CL}$ generated and interpreted the data and revised the manuscript for important intellectual content. TSD, SRF, and ABF interpreted the data and revised the manuscript for important intellectual content. All authors approved the final version of the manuscript.
Funding The Center for Dermatology Research is supported by an unrestricted educational grant from Galderma Laboratories.

Competing interests SRF is a consultant and speaker for Galderma, Connetics, Abbott Labs, Warner Chilcott, Centocor, Amgen, Photomedex, Genentech, Biogenldec, and Bristol Myers Squibb. SRF has received grants from Galderma, Connetics, Astellas, Abbott Labs, Warner Chilcott, Centocor, Amgen, Photomedex, Genentech, Biogenldec, Coria, Pharmaderm, Ortho Pharmaceuticals, Aventis Pharmaceuticals, Roche Dermatology, 3M, Bristol Myers Squibb, Stiefel, GlaxoSmithKline, and Novartis and has received stock options from Photomedex. ABF has received research, speaking and/or consulting support from Astellas, Amgen, Azai, Abbott, Galderma, Kikaku International, Stiefel, and Intendis. He is also employed by Merz Pharmaceuticals. EWJK, SAD, TSD, and H-CL have no conflicts to disclose.

Provenance and peer review Not commissioned; externally peer reviewed.

\section{REFERENCES}

1 Shekelle PG, Morton SC, Keeler EB. Costs and benefits of health information technology. Evid Rep Technol Assess 2006;132:1-71.

2 Hillestad R, Bigelow J, Bower A, et al. Can electronic medical record systems transform health care? Potential health benefits, savings, and costs. Health Aff (Millwood) 2005;24:1103-17.

3 Soper WD. Why I love my EMR. Fam Pract Manag 2002;9:35-8.

4 Wang SJ, Middelton B, Prosser LA, et al. A cost-benefit analysis of electronic medical records in primary care. Am J Med 2003;114:397-403.

5 Steinbrook R. Health care and the American Recovery and Reinvestment Act. N Eng J Med 2009;360:1057-60.

6 United States Department of Health and Human Services. Centers for Medicare and Medicaid Services. Electronic health records at a glance. July 13, 2010. https:// www.cms.gov/apps/media/press/factsheet.asp? Counter $=3788$ \&intNumPerPage $=10 \&$ checkDate $=\&$ checkKey $=\&$ srchType $=1 \&$ numDays $=3500 \&$ srchOpt $=0 \&$ srchData $=\&$ keywordType $=$ All\&chkNewsType $=6 \&$ intPage $=\&$ showAll $=\&$ pYear $=\& y e a r=\& d e s c=\& c b o O r d e r=$ date $($ accessed July 7, 2011).

7 United States Department of Health and Human Services. Centers for Medicare and Medicaid Services. CMS HER meaningful use overview. https://www.cms.gov/ EHRIncentivePrograms/30_Meaningful_Use.asp\#TopOfPage (accessed July 14, 2011).

8 Bowens FM, Frye PA, Jones WA. Health information technology: integration of clinical workflow into meaningful use of electronic health records. Perspect Health Inf Manag 2010;7:1d

9 Blumenthal D. Stimulating the adoption of health information technology. N Engl J Med 2009:360:1477-9.

10 Dolan PL. EMR adoption rates up, with small practices left behind. American Medical News. Nov 22, 2010. http://www.ama-assn.org/amednews/2010/11/22/ bisb1122.htm (accessed Aug 10, 2011).

11 DesRoches CM, Campbell EG, Rao SR, et al. Electronic health records in ambulatory care-a national survey of physicians. N Engl J Med 2008;359:50-60.

12 Gans D, Kralewski J, Hammons T, et al. Medical groups' adoption of electronic health records and information systems. Health Aff (Millwood) 2005:24:1323-33.

13 Miller RH, Sim I. Physicians' use of electronic medical records: barriers and solutions. Health Aff (Millwood) 2004;23:116-26.

14 Castillo VH, Martinez-Garcia Al, Pulido JR. A knowledge-based taxonomy of critical factors for adopting electronic health record systems by physicians: a systematic literature review. BMC Med Inform Decis Mak 2010;10:60.

15 Centers for Disease Control and Prevention. About the ambulatory health care surveys. http://www.cdc.gov/nchs/ahcd/about_ahcd.htm (accessed July 7, 2011).

16 National Center for Health Statistics. Health Indicators Warehouse: National Ambulatory Medical Care Survey (NAMCS). http://www.healthindicators.gov/ Resources/DataSources/NAMCS_74/Profile (accessed July 8, 2011).

17 Burt CW, Sisk JE. Which physicians and practices are using electronic medical records? Health Aff (Millwood) 2005;24:1334-43.

18 Audet A, Doty MM, Peugh J, et al. Information technologies: when will they make it into physicians' black bags? MedGenMed 2004;6:2.

19 Rittenhouse DR, Casalino LP, Shortell SM, et al. Small and medium-size physician practices use few patient-centered medical home processes. Health Aff (Millwood) 2011;30:1575-84.

20 United States Cong. Congressional Budget Office. Evidence on the costs and benefits of health information technology. May 2008. http://www.cbo.gov/ftpdocs/ 91xx/doc9168/05-20-HealthIT.pdf (accessed July 11, 2011).

21 Rubinsztain J. One-size EMR doesn't fit all. Healthcare Informatics online. http://www. gmed.com/docs/mediahits/Healthcare Informatics.pdf (accessed July 21, 2011).

22 Hsiao CJ, Decker SL, Hing E, et al. Most physicians were eligible for federal incentives in 2011, but few had EHR Systems that met meaningful-use criteria. Health Aff (Millwood) 2012;31:1100-7.

23 Hsiao CJ, Hing E, Socey TC, et al. Electronic health record systems and intent to apply for meaningful use incentives among office-based physician practices: United 
States, 2001-2011. NCHS data brief no 79. Hyattsville, MD: National Center for Health Statistics (NCHS), 2011.

24 Hsiao CJ, Hing E. Use and characteristics of electronic health record systems among office-based physician practices: United States, 2001-2012. NCHS data brief no. 111. Hyattsville, MD: National Center for Health Statistics (NCHS), 2012.

25 Dolan PL. EMR vendors stress usability to attract physicians. American Medical News. June 20, 2011. http://www.ama-assn.org/amednews/2011/06/20/bica0620. htm (accessed July 21, 2011).

26 Gadd CS, Penrod LE. Assessing physician attitudes regarding use of an outpatient EMR: a longitudinal, multi-practice study. Proc AMIA Symp 2001:194-8.
27 Joos D, Chen Q, Jijjis J, et al. An electronic medical record in primary care: impact on satisfaction, work efficiency and clinic processes. AMIA Annu Symp Proc 2006:394-8.

28 Buntin MB, Burke MF, Hoaglin MC, et al. The benefits of health information technology: a review of the recent literature shows predominantly positive results. Health Aff (Millwood) 2011;30:464-71.

29 Romano MJ, Stafford RS. Electronic health records and clinical decision support systems: impact on national ambulatory care quality. Arch Intern Med 2011;171:897-903.

30 Linder JA, Ma J, Bates DW, et al. Electronic health record use and the quality of ambulatory care in the United States. Arch Intern Med 2007;167:1400-5. 